\title{
AVALIAÇÃO DE GENÓTIPOS DE TRIGO ORIUNDOS DE CRUZAMENTO INTERESPECÍFICO E RADIAÇÃO GAMA NO ESTADO DE SÃO PAULO
}

\author{
C.E.O. CAMARGO ${ }^{1,5}$; A. TULMANN NETO ${ }^{2,5}$; A.W.P. FERREIRA FILHO'; J.G. FREITAS ${ }^{1,5}$, A. \\ PETTINELLI JUNIOR ${ }^{3}$; J.L. CASTRO ${ }^{4,5}$
}

'Instituto Agronômico de Campinas, C.P. 28, CEP: 13001-970- Campinas,SP

${ }^{2}$ Centro de Energia Nuclear na Agricultura/USP, C.P. 96, CEP: 13400-970- Piracicaba,SP

${ }^{3}$ Estação Experimental de Tatui-LAC, C.P. 33, CEP: 18270-000-Tatuí,SP

'Estação Experimental de Capao Bonito-IAC, C.P. 62, CEP: 18300-000-Capão Bonito,SP

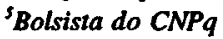

\begin{abstract}
RESUMO: Foram comparadas entre si e com dois controles vinte e três linhagens hexaplöides originárias de seleçōes realizadas em população submetida à radiação gama $(27,5 \mathrm{krad})$, em geração $\mathrm{F}_{4}$, do cruzamento interespecífico entre BH-1146 (Triticum aestivum L.) e Anhinga "S" $x$ Winged "S" (T. durum L.). Em nove ensaios em condiçōes de irrigação e de sequeiro, analisou-se uma série de características agronómicas. Em laboratório efetuaram-se estudos da tolerancia ao alumínio. As linhagens 11 e 19 de porte médio, com moderada resistência ao acamamento, tolerantes a toxicidade de alumínio destacaram-se quanto à produção de grãos. Sete linhagens apresentaram moderada resistência ao agente causal do ofdio. Todos os genotipos foram suscetiveis aos agentes causais das manchas foliares. Alguns dos genotipos poderiam ser utilizados em programas de cruzamento como fontes genéticas para plantas de porte baixo, de espiga comprida, de grande número de espiguetas por espiga, maior número de gräos por espiga, e maior número de grāos por espigueta e de grāos mais pesados. BH-1146 e sete das linhagens foram considerados os genótipos mais tolerantes à toxicidade de alumínio por por exibirem crescimento radicular apos serem cultivados em soluçōes nutritivas contendo $10 \mathrm{mg} /$ litro de $\mathrm{Al}^{+3}$.
\end{abstract}

Descritores: trigo, trigo duro, hibrido interespecfíco, genotipos, radiaçăo gama, caracteristicas agronômicas

\section{EVALUATION OF WHEAT GENOTYPES ORIGINATED FROM INTERESPECIFIC CROSSINGS AND GAMMA RADIATION}

\begin{abstract}
ARSTRACT: Twenty three inbred HEXAPLOID wheat lines were evaluated. They were originated by selections made in populations submited to gamma radiation $(27.5 \mathrm{krad})$, in the $F_{4}$ generation, from the interespecific hybrid between BH-1146 (Triticum aestivum L.) and Anhinga "S" $x$ Winged "S" (Triticum durum L.) and the cultivars BH1146 and Yavaros "S" (T. durum L.). Nine trials were carried out with irrigation and in upland conditions. Several agronomic characteristics were assessed. Under laboratory conditions the genotypes were evaluated with respect to Al toxicity using nutrient solutions. Semidwarf lines 11 and 19, with moderate lodging resistance, medium cycle from emergence to flowering, tolerance to aluminum toxicity, were the most productive. Seven lines showed resistance to the causal agent of mildew, but all genotypes were susceptible to the causal agents of leaf spots. Some of the genotypes could be used in cross breeding as genetic sources for short plant, long head, large number of spikelets per head, large number of grains per head and per spikelet and for heavy grains. BH-1146 and seven from the 23 lines were considered the most tolerant to aluminum toxicity, presenting good regrowth after treatment in nutrient solutions with $10 \mathrm{mg} / \mathrm{hiter}$ of $\mathrm{Al}^{+3}$.

$\mathrm{Key}$ Woris: wheat, durum wheat, interspecific hybrid, genotypes, gamma-radiation, agronodic characteristics

\section{INTRODUÇÃO}

Existem dois tipos principais de trigo comercial: o para pão ou panificável (Triticum aestivum L.), hexaploide, apresentando três genomas (A, B e D), que representa a totalidade da

triticultura brasileira e o trigo duro ou trigo para macarrão (Triticum durum L.), tetraploide, apresentando dois genomas (A e B) (HANSON et al. , 1982). O Brasil não produz e não importa o trigo duro, sendo portanto usado o $T$. aestivum $L$., inadequadamente, para produção de massas.
\end{abstract}


As variedades de trigo duro, por não apresentarem o genoma $D$, no qual estão localizados os genes que conferem a tolerância ao $\mathrm{Al}^{3+}$, são muito sensíveis aos solos ácidos mostrando baixa produtividade nessas condições (CAMARGO et al., 1992).

O Instituto Agronômico tem procurado através de cruzamentos entre cultivares dessas duas espécies aumentar a variabilidade genética dos trigos hexaplóides e por conseguinte selecionar linhagens de alto potencial produtivo, de porte semi-anão e com qualidades tecnológicas adequadas para a fabricação de pães, massas e biscoitos ( $\mathrm{S} A ̃$ PAULO, 1990-92).

Os efeitos dos mutagênicos podem ser utilizados para a resolução de alguns problemas específicos no melhoramento de plantas, tais como facilitar a recombinação em cruzamento (BATHIA, 1977). Com este objetivo, no melhoramento de trigo na China, por exemplo, a radiação gama tem sido utilizada com sucesso em sementes de parentais ou de gerações iniciais após o cruzamento. Alguns autores obtiveram aumento na segregação nas populações segregantes em geração $F_{2}$, para altura de planta, número de espigas por planta e outras características, através da irradiação dos parentais, antes do cruzamento (WU, 1986). Em outro trabalho realizado na China (WANG et al., 1986) os autores irradiaram sementes $F_{1}$ obtidas de cruzamentos entre quatro variedades. Comparando as gerações $\mathrm{F}_{2} \mathrm{M}_{2}$ com os controles $\mathrm{F}_{2}$, concluiram que a amplitude de segregação, para várias características, foi maior em $\mathrm{F}_{2} \mathrm{M}_{2}$. Além disso, apareceram nos segregantes desta geração, características não encontradas nos parentais. Em certos casos, variedades mutantes foram obtidas da irradiação da geração $\mathrm{F}_{3}$. De acordo com esse trabalho, dos 48 cultivares mutantes de trigo, 23 foram obtidos da irradiação de híbridos. Ainda na China, a irradiação de sementes $F_{1}$ de cruzamento entre triticale e trigo comum, resultou em aumento da fertilidade das plantas híbridas em geração $F_{1}$ e ampliação da segregação em $F_{2}$ (ZHEN et al., 1986). Sementes de híbridos entre triticales octoploides e trigo comum foram também irradiados neste país, com o objetivo de induzir translocações cromossômicas para transferência de fragmentos cromossômicos ou genes de centeio para os genomas A, B e D de trigo, selecionando-se linhas que apresentaram segregação de interesse (LI et al., 1986).

Um trabalho conjunto entre o Instituto Agronômico e o Centro de Energia Nuclear na
Agricultura foi iniciado em 1985 com o objetivo de selecionar genótipos melhorados de trigo comum através da irradiação com raios gama (27,5 krad) de sementes híbridas em geração $\mathrm{F}_{4}$ do cruzamento entre o cultivar BH-1146 ( $T$. aestivum $\mathrm{L}$.) de ciclo precoce, porte alto e tolerante à toxicidade de $\mathrm{Al}^{3+}$ e a linhagem (Anhinga " $S$ " $x$ Winged " $S$ ") $(T$. durum L.) de ciclo muito tardio, porte semi-anão e sensivel à toxicidade de $\mathrm{Al}^{3+}$, visando o aumento na recombinação genética.

O presente trabalho teve por objetivo avaliar, em condição de sequeiro e de irrigação por aspersão, o comportamento de linhagens provenientes do cruzamento referido anteriormente em comparação com o cultivar de trigo comum BH-1146 e o cultivar de trigo duro Yavaros "S".

\section{MATERIAL E MÉTODOS}

Vinte e três linhagens hezaplóides oriundas de seleções realizadas em populações híbridas irradiadas provenientes da irradiação de sementes do cruzamento BH-1146 x (Anhinga "S" $\mathrm{x}$ Winged "S") em geração F4 foram avaliadas.

Como controles, utilizaram-se os seguintes cultivares: $\mathrm{BH}-1146$, selecionado no Instituto Agronômico de Minas Gerais, de porte alto, suscetível aos agentes causais da ferrugem-docolmo e da folha, ciclo precoce, tolerante à toxicidade de $\mathrm{Al}^{3+}$, e pertencente a espécie $T$. aestivum $\mathrm{L}$., bem como Yavaros "S", introduzido do Centro Internacional de Melhoramento de Milho e Trigo do Mexico, de porte semi-anão, resistente às ferrugens, sensível à toxicidade de $\mathrm{Al}^{3+} \mathrm{e}$ pertencente à espécie $T$. durum $\mathrm{L}$.

Utilizou-se o delineamento estatístico de blocos ao acaso, com três repetições por local. Cada ensaio foi constituido de 75 parcelas, cada uma formada de seis linhas de $3 \mathrm{~m}$ de comprimento, espaçadas de $0,20 \mathrm{~m}$.

A semeadura foi feita na base de 80 sementes viáveis por metro linear de sulco, equivalendo a 1.440 sementes por parcela, com uma área útil de colheita de $3,6 \mathrm{~m}^{2}$. A quantidade de fertilizante empregada $\left(\mathrm{N}, \mathrm{P}_{2} \mathrm{O}_{5}\right.$ e $\left.\mathrm{K}_{2} \mathrm{O}\right)$ nos diferentes ensaios baseou-se nas tabelas de adubação do instituto agronômico (RAIJ et al., 1985).

No Centro Experimental de Campinas e na Estação Experimental de Tatuí, conduziram-se, com irrigação por aspersão, três ensaios, em 1990, 1991 e 1992. Em condição de sequeiro, na Estação 
Experimental de Capão Bonito realizaram-se dois ensaios, em 1991 e 1992 e na Fazenda Santa Lúcia, município de Cruzália, Vale do Paranapanema, instalou-se um ensaio em 1992.

Retiraram-se amostras compostas dos solos dos locais estudados, nas profundidades de 0-20, 20-40 e 40-60 cm, encontrando-se na TABELA 1 os resultados das análises.

Coletaram-se os seguintes dados:

Ferrugem-do-colmo e da-folha: Efetuou-se a avaliação dessas doenças causadas, respectivamente, por Puccinia graminis f.sp. tritici e $P$. recondita, através de observação geral, em cada parcela, no colmo e nas folhas superiores das plantas, no estádio de início de maturação, em condições naturais de infecção, usando-se a escala modificada de Cobb, utilizada por SCHRAMM et al. (1974). Essa escala vai de 0 a $100 \%$ por área foliar infectada, complementada pelo tipo de ração: $\mathbf{S}=$ suscetível (uredossoro grande, coalescente, sem necrose e sem clorose); MS = moderadamente suscetível (uredossoro médio); $M=$ intermediária (diversos tipos de reação); $M R=$ moderadamente resistente (uredossoro pequeno); $\mathbf{R}=$ resistente (uredossoro minúsculo, rodeado de áreas necróticas).

Mancha-da-folha: Procedeu-se a avaliação de manchas foliares causadas por Helminthosporium sp e/ou Septoria sp. em planta adulta, em condições naturais de infecção, empregando-se uma escala de 0 a $99 \%$ de área infectada, apresentada por MEHTA (1978), onde zero é considerado imune; 1 a $5 \%$ resistente; 6 a $25 \%$ moderadamente resistente; 26 a $50 \%$ suscetível e 51 a $99 \%$ altamente suscetível.

Ó́dio: A avaliação do oídio pelo fungo Erysiphe graminis sp. tritici foi feita de maneira idêntica à citada para mancha da folha.

Ciclo da emergência ao florescimento: Fazendose contagens por parcela do número de dias da emergência das plântulas ao pleno florescimento.

Plantas acamadas: Considerando a porcentagem de plantas acamadas em cada parcela, por avaliação visual próxima a época de maturação.

Altura das plantas: Medida no campo, na época de maturação, a distância, em centímetros, do nível do solo ao ápice da espiga, com exclusão das aristas, e levando-se em consideração a média de diferentes pontos em cada parcela.

Comprimento da espiga: Considerando-se o comprimento médio, em centímetros, de dez espigas tomadas ao acaso em cada parcela, excluindo-se as aristas.

Espiguetas: Computando o número médio de espiguetas de dez espigas tomadas ao acaso em cada parcela.

Grãos por espiga: Considerando o número médio de grãos contados em dez espigas colhidas ao acaso, em cada parcela.

Grãos por espigueta: Calculando-se pela divisão do número total de grãos de dez espigas coletadas ao acaso, em, cada parcela, pelo número total de suas espiguetas.

Peso de cem grãos: Levando-se em conta o peso, em gramas, de cem grãos tomados ao caso na produção total de cada parcela.

Rendimento: Considerando-se a produção total de grãos obtida nas seis linhas de cada parcela.

As características comprimento da espiga, número de espiguetas por espiga, número de grãos por espiga e por espigueta e peso de cem grãos foram avaliadas somente nos ensaios de Campinas (1991) e Tatuí (1992) e o ciclo da emergência ao florescimento apenas nos de Campinas (1990), Tatuí (1990) e Capão Bonito (1991 e 1992).

Analisaram-se as variâncias conjuntas para os experimentos de Campinas, Tatuí e Capão Bonito para os nove experimentos, independentemente dos locais onde foram instalados, para produção de grãos e para os de Campinas (1991) e Tatuí (1992) para comprimento da espiga, numero de espiguetas por espiga, número de grãos por espiga e por espigueta e peso de cem grãos, para detectar pelo teste $F$, ao nível de $5 \%$ as significâncias dos efeitos de experimentos, genótipos e interação genótipos $x$ experimentos. 0 teste de Tukey ao nível de $5 \%$ foi empregado para a comparação dos genótipos nos grupos de experimentos, usando-se como estimativa do desvio padrão residual o quadrado médio da interação genótipos $\mathrm{x}$ esperimentos $\mathrm{da}$ análise da variância. 
TABELA 1 - Análises compostas dos solos dos locais onde foram instalados os ensaios nas profundidades de 0-20, 20-40 e 40-60 $\mathrm{cm}^{(1)}$

\begin{tabular}{|c|c|c|c|c|c|c|c|c|c|c|c|c|}
\hline & \multicolumn{3}{|c|}{ Tatuí } & \multicolumn{3}{|c|}{ Campinas } & \multicolumn{3}{|c|}{ Capão Bonito } & \multicolumn{3}{|c|}{ Cruzália } \\
\hline & $0-20$ & $20-40$ & $40-60$ & $0-20$ & $20-40$ & $40-60$ & $0-20$ & $20-40$ & $40-60$ & $0-20$ & $20-40$ & $40-60$ \\
\hline $\begin{array}{l}\text { P.resina } \\
\left(\mu \mathrm{g} / \mathrm{cm}^{3}\right)\end{array}$ & 37 & 19 & 10 & 23 & 6 & 4 & 19 & 16 & 14 & 40 & 32 & 19 \\
\hline M.O. \% & 2,50 & 2,20 & 1,90 & 3,20 & 2,50 & 1,80 & 2,30 & 2,50 & 2,20 & 3,0 & 3,0 & 1,80 \\
\hline $\mathrm{pH}\left(\mathrm{CaCl}_{2}\right)$ & 5,50 & 5,00 & 4,50 & 5,30 & 4,70 & 4,70 & 4,70 & 4,70 & 4,70 & 3,2 & 5,20 & 5,00 \\
\hline $\begin{array}{l}\mathrm{K}(\mathrm{meq} / \\
\left.100 \mathrm{~cm}^{3}\right)\end{array}$ & 0,43 & 0,27 & 0,22 & 0,33 & 0,18 & 0,12 & 0,13 & 0,11 & 0,09 & 0,25 & 0,25 & 0,16 \\
\hline $\begin{array}{l}\mathrm{Ca}(\mathrm{meq} / \\
\left.100 \mathrm{~cm}^{3}\right)\end{array}$ & 4,40 & 3,50 & 2,50 & 3,10 & 1,80 & 1,40 & 1,80 & 1,70 & 1,70 & 3,60 & 3,30 & 2,20 \\
\hline $\begin{array}{l}\mathrm{Mg}(\mathrm{meq} / \\
\left.100 \mathrm{~cm}^{3}\right)\end{array}$ & 1,50 & 1,40 & 1,10 & 1,20 & 0,90 & 0,70 & 0,70 & 0,70 & 0,70 & 0,90 & 0,80 & 0,70 \\
\hline $\begin{array}{l}\mathrm{H}+\mathrm{Al}(\mathrm{meq} / \\
\left.100 \mathrm{~cm}^{3}\right)\end{array}$ & 3,10 & 4,70 & 6,50 & 3,80 & 4,70 & 3,80 & 6,50 & 6,50 & 6,50 & 3,40 & 3,40 & 3,40 \\
\hline $\begin{array}{l}S(\mathrm{meq} / \\
\left.100 \mathrm{~cm}^{3}\right)\end{array}$ & 6,30 & 5,20 & 3,80 & 4,60 & 2,90 & 2,20 & 2,60 & 2,50 & 2,50 & 4,80 & 4,40 & 3,10 \\
\hline $\begin{array}{l}T(\mathrm{meq} / \\
\left.100 \mathrm{~cm}^{3}\right)\end{array}$ & 9,40 & 9,90 & 10,30 & 8,40 & 7,60 & 6,00 & 9,10 & 9,00 & 9,00 & 8,20 & 7,80 & 6,50 \\
\hline v \% & 67 & 52 & 37 & 55 & 38 & 37 & 29 & 28 & 28 & 58 & 56 & 47 \\
\hline
\end{tabular}

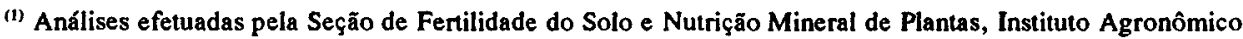

Foram feitas análises de variâncias conjuntas para as cacterísticas altura das plantas e ciclo da emergência ao florescimento considerando a média dessas características em cada um dos experimentos nos quais foram avaliadas, para detectar pelo teste $F$, ao nivel de $5 \%$, as significâncias dos efeitos de genótipos e experimentos. A comparação das médias dos genótipos para essas características foi feita também pelo teste de Tukey ao nível de $5 \%$.

As plântulas das linhagens e dos cultivares foram testadas em condição de laboratório, para tolerância a $0,3,6$ e $10 \mathrm{mg} /$ litro de $\mathrm{Al}^{3+} \mathrm{em}$ soluções nutritivas, conforme CAMARGO \& OLIVEIRA (1981) e CAMARGO et al. (1987). O delineamento estatístico empregado foi o de blocos ao acaso com parcelas subdivididas, sendo as parcelas compostas por quatro concentrações de alumínio e as subparcelas, pelos genótipos de trigo. Realizaram-se duas repetições para cada solução tratamento. Na análise dos dados considerou-se a média de comprimento da raiz primária central das dez plântulas de cada genótipo, em 72 horas de crescimento nas soluções nutritivas completas sem alumínio, que se seguiu a 48 horas de crescimento nas soluções de tratamento contendo quatro diferentes concentrações de alumínio.

\section{RESULTADOS E DISCUSSÃO}

Os quadrados médios da análise da variância conjunta das produções médias de grãos dos genótipos dos ensaios em condição de irrigação por aspersão, em Tatuí, mostraram efeitos significativos para experimentos, genótipos e interação genótipos $\mathrm{x}$ experimentos.

Considerando-se a média dos três experimentos de Tatuí realizados em 1990, 1991 e 1992 - TABELA 2 - observou-se que a linhagem $11(4.436 \mathrm{~kg} / \mathrm{ha})$ foi a mais produtiva, diferindo, porém somente das linhagens $5,8,15$ e 22, e do cultivar Yavaros "S". 
TABELA 2 - Rendimento (1) dos genótipos de trigo nos ensaios de Tatuí, Campinas, Capão Bonito e Cruzália

\begin{tabular}{|c|c|c|c|c|c|}
\hline \multirow{3}{*}{ Linhagens e Cultivares } & Tatuí & Campinas & C.Bonito & Cruzália & \multirow{2}{*}{$\begin{array}{r}\text { Media } \\
\text { Geral } \\
\end{array}$} \\
\hline & $1990 / 1992$ & $1990 / 92$ & $1991 / 92$ & 1992 & \\
\hline & \multicolumn{5}{|c|}{$\mathrm{kg} / \mathrm{ha}$} \\
\hline BH-1146 & 2966 a-c & 2798 a-d & 1995 a-d & $1990 \mathrm{ab}$ & $2586 \mathrm{c}-\mathrm{h}$ \\
\hline Yavaros "S" & $2671 \mathrm{bc}$ & $2123 \mathrm{~d}$ & $241 \mathrm{f}$ & $1213 \mathrm{~cd}$ & $1786 \mathrm{i}$ \\
\hline L-1 & $3708 a-c$ & $3350 \mathrm{a}-\mathrm{c}$ & 1667 a-e & $2237 a$ & $2972 c-f$ \\
\hline $\mathbf{L}-2$ & 2956 a-c & 2918 a-d & $829 c-f$ & $1191 \mathrm{~cd}$ & $2274 \mathrm{f}-\mathrm{i}$ \\
\hline L-3 & 3010 a-c & $3057 \mathrm{a}-\mathrm{d}$ & 1519 a-f & 1721 a-d & $2551 \mathrm{c}-\mathrm{h}$ \\
\hline$L-4$ & 3145 a-c & 3174 a-d & 972 b-f & $1062 d$ & $2440 \mathrm{e}-\mathrm{i}$ \\
\hline L-5 & $2698 \mathrm{bc}$ & 3217 a-d & 954 b-f & $1316 \mathrm{~b}-\mathrm{d}$ & $2330 \mathrm{e}-\mathrm{i}$ \\
\hline L-6 & 3378 a-c & $2702 a-d$ & 1579 a-f & $1142 \mathrm{~cd}$ & $2504 \mathrm{~d}-\mathrm{i}$ \\
\hline L-7 & 3479 a-c & 2793 a-d & 1695 a-e & 1389 b-d & $2622 b-g$ \\
\hline L-8 & $2149 c$ & $2308 \mathrm{~cd}$ & 884 b-f & $1395 \mathrm{~b}-\mathrm{d}$ & $1837 \mathrm{hi}$ \\
\hline L-9 & $3400 a-c$ & 3091 a-d & 1523 a-f & $1410 \mathrm{~b}-\mathrm{d}$ & $2659 \mathrm{~b}-\mathrm{g}$ \\
\hline L-10 & 3421 a-c & 3079 a-d & 1505 a-f & $1704 a-d$ & $2690 \mathrm{~b}-\mathrm{g}$ \\
\hline L-11 & $4436 a$ & $3906 a$ & $2264 \mathrm{ab}$ & $1857 a-c$ & $3490 a$ \\
\hline L-12 & 3199 a-c & 2794 a-d & $1102 \mathrm{a}-\mathrm{f}$ & 1750 a-d & 2437 e-i \\
\hline L-13 & $3854 \mathrm{ab}$ & 3202 a-d & $1500 a-f$ & 1773 a-d & $2882 a-g$ \\
\hline L-14 & 3501 a-c & $2529 b-d$ & 1199 a-f & 1577 a-d & 2452 e-i \\
\hline L-15 & $2735 b c$ & 3067 a-d & 357 ef & $1304 b-d$ & $2158 \mathrm{~g}-\mathrm{i}$ \\
\hline L-16 & 3564 a-c & 3074 a-d & 1889 a-d & $1995 a b$ & $2854 \mathrm{a}-\mathrm{g}$ \\
\hline L-17 & 2837 a-c & 2942 a-d & $681 \mathrm{~d}-\mathrm{f}$ & $1307 b-d$ & $2223 \mathrm{f}-\mathrm{i}$ \\
\hline L-18 & 3589 a-c & 2540 b-d & 1653 a-f & $1858 \mathrm{a}-\mathrm{c}$ & 2617 b-g \\
\hline L-19 & $4075 a b$ & $3903 \mathrm{a}$ & $2500 a$ & $1407 b-d$ & $3371 \mathrm{ab}$ \\
\hline L-20 & $3859 a b$ & $3613 a b$ & $1926 \mathrm{a}-\mathrm{d}$ & $1445 b-d$ & 3079 a-e \\
\hline L-21 & $4124 a b$ & $3628 a b$ & $2171 \mathrm{a}-\mathrm{c}$ & 1591 a-d & $3243 a-c$ \\
\hline L-22 & 2796 bc & 2760 a-d & 1324 a-f & $1376 b-d$ & $2299 \mathrm{f}-\mathrm{i}$ \\
\hline L-23 & $4201 \mathrm{ab}$ & $3763 a$ & 2070 a-d & $1541 a-d$ & $3286 a-c$ \\
\hline F (Experimentos) & $68,53 *$ & $205,72 *$ & 2,18 & - & $162,06 *$ \\
\hline F (Genótipos) & $3,49 *$ & $4,17^{*}$ & $5,74 *$ & $4,87^{*}$ & $9,04 *$ \\
\hline$F(G \times E)$ & $3,06 *$ & $1,80 *$ & $1,92 *$ & - & $2,64 *$ \\
\hline d.m.s. (Tukey a 5\%) & 1624 & 1225 & 1414 & 743 & 762 \\
\hline c.V.\% & 15,39 & 16,64 & 29,92 & 15,23 & 17,97 \\
\hline
\end{tabular}

*Significativo ao nivel de $5 \%$.

(1) Médias seguidas de uma mesma letra em comum não diferem pelo teste de Tukey. 
Os quadrados médios da análise de variância conjunta das produções médias de grãos dos genótipos estudados nos ensaios em condiçao de irrigação, em Campinas, mostraram efeitos significativos para experimentos, genótipos e interação genótipos $\mathrm{x}$ experimentos.

Considerando-se a média dos três experimentos de Campinas, realizados em 1990, 1991 e 1992 (TABELA 2) observou-se que a linhagem 11 (3.906 kg/ha) e 19 (3.903 kg/ha) foram as mais produtivas, diferindo porém somente das linhagens 8, 14 e 18, e do cultivar Yavaros "S".

Os quadrados médios da análise da variância conjunta das produções médias de grãos dos genótipos dos ensaios em condição de sequeiro e de solo ácido, com porcentagem de saturação por saturação por bases na camada arável de 29 TABELA 1, em Capão Bonito (1991 e 1992) mostraram efeitos significativos para genótipos e interação genótipos $\mathrm{x}$ experimentos e efeito não significativo para experimentos.

Considerando-sea média dos dois experimentos de Capão Bonito (TABELA 2), verificou-se que a linhagem $19(2.500 \mathrm{~kg} / \mathrm{ha})$ foi a que exibiu a maior produção de grãos, diferindo, porém, somente das linhagens $2,4,5,8,15$ e 17 e do cultivar de trigo duro Yavaros "S". O cultivar BH1146 , tolerante e o cultivar de trigo duro Yavaros "S", sensível à toxicidade de $\mathrm{Al}^{3+}$ apresentaram produções médias de 1995 e 241 kg/ha, em Capão Bonito, estes resultados confirmaram os obtidos por CAMARGO et al. (1993) avaliando cultivares de trigo e de trigo duro em solo ácido.

No ensaio de Cruzália (1992) destacou-se pela produtividade em condição de sequeiro e solo corrigido (TABELA 1) a linhagem $1(2.237 \mathrm{~kg} / \mathrm{ha})$ porém somente diferiu das linhagens $2,4,5,6,7$, $8,9,15,17,19,20$ e 22 além da v. Yavaros "S".

A análise de variância, para produção de grãos, dos genótipos estudados nos nove ensaios, no período 1990-92, mostraram quadrados médios com efeitos significativos para experimentos, genótipos e interação experimentos $\mathrm{x}$ genótipos. Considerando-seas produções médias dos genótipos nos nove ensaios (TABELA 2), verificou-se pelo teste de Tukey, ao nível de $5 \%$, que as linhagens $11(3.490 \mathrm{~kg} / \mathrm{ha})$ e $19(3.371 \mathrm{~kg} / \mathrm{ha})$ foram as mais produtivas diferindo significativamente dos cultivares controles. A linhagem 11 diferiu das demais avaliadas com exceção das linhagens 13 , $16,19,20,21$ e 23 e mostrou grande estabilidade de produção $e$ ampla adaptação às diferentes condiçôes de ambiente.
Os graus médios de infecção de ferrugem-do-colmo e da-folha, e de oídio nos genótipos de cada experimento, no período 1990-92, achamse na TABELA 3.

Não houve no período condiçôes climáticas favoráveis para infecção dos agentes causais das ferrugens. Somente no ensaio de Tatuí (1990) houve ocorrência de apenas algumas pústulas de ferrugem do colmo na linhagem 3 . Em relação à ferrugem-da-folha as linhagens 9 em Tatuí (1990) e $12 \mathrm{em} \mathrm{Cruzália} \mathrm{(1992)} \mathrm{mostraram} \mathrm{graus} \mathrm{médios}$ de infecção de $20 \mathrm{~S}$ e $10 \mathrm{~S}$, respectivamente, sendo portanto os genótipos mais sucetiveis entre os estudados. Os demais tratamentos, com exceção das linhagens $3,4,8,11,16,20,21$ e 22 exibiram imunidade a essa ferrugem.

As linhagens $4,15,18,19,20,21$ e 23 foram consideradas moderadamente resistentes ao oídio por apresentarem uma porcentagem de área infectada não superior a 25 , em pelo menos um dos locais considerados (MEHTA, 1978). Os demais genótipos foram sensiveis, sendo que o cultivar BH-1146 e as linhagens $1,5,9$ e 14 foram considerados altamente sensíveis por mostrar uma porcentagem de área infectada entre 51 e $99 \%$, em pelo um dos experimentos.

Empregando-se a escala proposta por MEHTA (1978), todos os genótipos avaliados foram suscetíveis aos agentes causais das manchas foliares por apresentar uma porcentagem de área infectada entre 25 e 50 , em pelo menos em dois locais avaliados (TABELA 4). As linhagens 2, 3, $4,5,6,7,9,10,11,15,19,21$ e 22 foram altamente suscetíveis por mostrar uma porcentagem de área foliar infectada entre 51 e 99 , em pelo menos um experimento.

A altura média das plantas dos genótipos estudados nos nove experimentos encontram-se na TABELA 5: o cultivar BH-1146 mostrou as plantas mais altas, diferindo significativamente dos demais genótipos avaliados com exceção das linhagens 12 , 13 e 14. O cultivar de trigo duro Yavaros " $S$ " apresentou as plantas mais baixas, porém somente não diferindo das linhagens $3,5,6,15$ e 17 . O cultivar BH-1146 e a linhagem 13 apresentaram uma porcentagem média de plantas acamadas de 53 e 42 , respectivamente, que foi associada a um porte de planta alta (TABELA 5). O cultivar de trigo duro Yavaros "S" e as linhagens 5, 11, 15, 17, 18, $19,20,21$ e 23 apresentaram uma porcentagem de plantas acamadas entre 2 e 20, associado a um porte de planta médio a baixo, estando, portanto, entre os genótipos com potencial de cultivo em condições de irrigação por aspersão. 
TABELA 3 - Graus médios de infecção de ferrugem-do-colmo e da-folha, e oídio nos ensaios de Tatuí, Campinas e Cruzália.

\begin{tabular}{|c|c|c|c|c|c|c|c|}
\hline \multirow{3}{*}{$\begin{array}{c}\begin{array}{c}\text { Linhagens e } \\
\text { cultivares }\end{array} \\
\text { BH-1146 }\end{array}$} & \multirow{3}{*}{$\begin{array}{c}\text { ferrugem- } \\
\text { do-colmo } \\
\text { Tatuí } \\
1990 \\
0\end{array}$} & \multicolumn{3}{|c|}{ ferrugem da folha } & \multicolumn{3}{|c|}{ Oídio } \\
\hline & & \multirow{2}{*}{$\begin{array}{c}\text { Tatuí } \\
1990\end{array}$} & \multirow{2}{*}{$\begin{array}{c}\begin{array}{c}\text { Cruzália } \\
1992\end{array} \\
0\end{array}$} & \multirow{2}{*}{$\begin{array}{c}\begin{array}{c}\text { Campinas } \\
1992\end{array} \\
0\end{array}$} & \multirow{2}{*}{$\begin{array}{c}\begin{array}{c}\text { Tatuí } \\
1990\end{array} \\
10\end{array}$} & \multicolumn{2}{|c|}{$\begin{array}{c}\text { Campinas } \\
19911992 \\
\end{array}$} \\
\hline & & & & & & 60 & 30 \\
\hline Yavaros "S" & 0 & 0 & 0 & 0 & 5 & 40 & 30 \\
\hline L-1 & 0 & 0 & 0 & 0 & 10 & 60 & 30 \\
\hline L-2 & 0 & 0 & 0 & 0 & 5 & 40 & 10 \\
\hline L-3 & tS & 5S & 0 & 0 & 0 & 30 & 10 \\
\hline$L-4$ & 0 & 0 & $\mathbf{t S}$ & 0 & 0 & 20 & 5 \\
\hline $\mathrm{L}-5$ & 0 & 0 & 0 & 0 & 10 & 70 & 30 \\
\hline L-6 & 0 & 0 & 0 & 0 & 0 & 50 & 40 \\
\hline$L-7$ & 0 & 0 & 0 & 0 & 0 & 50 & 30 \\
\hline L-8 & $\mathbf{0}$ & 0 & $5 S$ & 0 & 0 & 50 & 30 \\
\hline L-9 & 0 & $20 S$ & 0 & 0 & 5 & 60 & 20 \\
\hline L-10 & 0 & $\mathbf{0}$ & 0 & 0 & 0 & 40 & 30 \\
\hline L-11 & $\mathbf{0}$ & $5 S$ & $5 S$ & 0 & 0 & 30 & 20 \\
\hline L-12 & 0 & $\mathbf{0}$ & $10 \mathrm{~S}$ & $\mathbf{0}$ & 0 & 30 & 10 \\
\hline L-13 & 0 & 0 & 0 & 0 & 5 & 30 & 20 \\
\hline L-14 & 0 & 0 & 0 & 0 & 0 & 60 & 20 \\
\hline L-15 & 0 & 0 & 0 & 0 & 5 & 20 & 20 \\
\hline L-16 & 0 & ts & 0 & 0 & 0 & 30 & 20 \\
\hline L-17 & 0 & 0 & 0 & 0 & 10 & 30 & 20 \\
\hline L-18 & 0 & 0 & 0 & 0 & 0 & 20 & 20 \\
\hline L-19 & 0 & 0 & 0 & 0 & 0 & 20 & 5 \\
\hline $\mathrm{L}-20$ & 0 & 0 & 0 & $\mathrm{tS}$ & 0 & 10 & 5 \\
\hline $\mathrm{L}-21$ & 0 & ts & 0 & 0 & 0 & 10 & 5 \\
\hline $\mathbf{L}-22$ & 0 & $5 S$ & 0 & $5 S$ & 0 & 50 & 3 \\
\hline L-23 & 0 & 0 & 0 & 0 & 0 & 20 & 10 \\
\hline
\end{tabular}

$\mathrm{t}=$ traço (algumas pústulas); $\mathrm{S}=$ reação de suscetibilidade 
TABELA 4 - Graus médios de infecção de mancha da folha nos ensaios de Tatuí, Campinas, Capão Bonito e Cruzália.

\begin{tabular}{|c|c|c|c|c|c|c|c|c|}
\hline \multirow{2}{*}{$\begin{array}{l}\text { Linhagens e } \\
\text { Cultivares }\end{array}$} & \multicolumn{3}{|c|}{ Tatuí } & \multicolumn{2}{|c|}{ Campinas } & \multicolumn{2}{|c|}{ Capão Bonito } & \multirow{2}{*}{$\begin{array}{c}\text { Cruzália } \\
1992\end{array}$} \\
\hline & 1990 & 1991 & 1992 & 1990 & 1992 & 1991 & 1992 & \\
\hline BH-1146 & 30 & 10 & 20 & 40 & 20 & 30 & 20 & 50 \\
\hline Yavaros "S" & 20 & 10 & 10 & 20 & 30 & 30 & 40 & 40 \\
\hline L-1 & 20 & 20 & 10 & 40 & 30 & 30 & 40 & 50 \\
\hline L-2 & 40 & 40 & 10 & 40 & 20 & 40 & 40 & 60 \\
\hline L-3 & 20 & 30 & 20 & 20 & 20 & 30 & 40 & 60 \\
\hline L-4 & 30 & 30 & 20 & 20 & 20 & 40 & 60 & 60 \\
\hline L-5 & 20 & 20 & 10 & 40 & 30 & 20 & 50 & 60 \\
\hline L-6 & 30 & 20 & 20 & 40 & 30 & 30 & 30 & 80 \\
\hline L-7 & 40 & 20 & 10 & 40 & 40 & 40 & 30 & 60 \\
\hline L-8 & 40 & 10 & 10 & 20 & 20 & 40 & 20 & 40 \\
\hline L-9 & 40 & 20 & 10 & 40 & 20 & 30 & 30 & 60 \\
\hline L-10 & 40 & 30 & 10 & 40 & 20 & 20 & 20 & 80 \\
\hline L-11 & 40 & 40 & 10 & 40 & 30 & 30 & 40 & 60 \\
\hline L-12 & 40 & 20 & 10 & 40 & 20 & 50 & 30 & 40 \\
\hline L-13 & 20 & 10 & 10 & 40 & 20 & 30 & 40 & 50 \\
\hline L-14 & 40 & 40 & 20 & 20 & 10 & 20 & 30 & 40 \\
\hline L-15 & 40 & 20 & 20 & 20 & 30 & 40 & 30 & 60 \\
\hline L-16 & 10 & 20 & 10 & 20 & 20 & 20 & 30 & 30 \\
\hline L-17 & 40 & 20 & 20 & 20 & 30 & 30 & 40 & 40 \\
\hline L-18 & 10 & 20 & 10 & 20 & 20 & 20 & 30 & 20 \\
\hline L-19 & 30 & 40 & 10 & 20 & 30 & 30 & 20 & 60 \\
\hline L-20 & 20 & 20 & 20 & 20 & 20 & 20 & 40 & 50 \\
\hline L-21 & 20 & 30 & 20 & 20 & 40 & 30 & 30 & 60 \\
\hline L-22 & 30 & 20 & 20 & 40 & 30 & 30 & 30 & 70 \\
\hline L-23 & 40 & 20 & 10 & 40 & 20 & 20 & 30 & 50 \\
\hline
\end{tabular}

Os ciclos médios, em dias da emergência ao florescimento dos genótipos estudados nos ensaios de Campinas (1990), Tatuí (1990) e Capão Bonito (1991 e 1992) encontram-se na TABELA 5: Yavaros " $S$ " foi o mais tardio para florescer diferindo significativamente somente das linhagens $1,2,4,5,8$ e 9 , que foram as mais precoces. A linhagem 5 por apresentar ao mesmo tempo ciclo precoce e porte baixo, mostrou ser uma fonte genética de interesse ao programa de melhoramento do Instituto Agronômico, para essas características.
Os quadrados médios das análises da variância conjunta para comprimento da espiga, número de espiguetas por espiga, número de grãos por espiga e por espigueta e peso de cem grãos dos genótipos dos ensaios de Campinas (1991) e Tatuí (1992) - TABELA 6 - mostraram, para todas as características consideradas, efeitos significativos para experimentos, genótipos e interação genótipos $x$ experimentos, com exceção da interação $G \times E$ para comprimento da espiga. 
TABELA 5 - Altura média das plantas ${ }^{(1)}$, porcentagem média de acamamento e ciclo da emergência no florescimento ${ }^{(1,2)}$ dos genótipos de trigo nos ensaios de Tatuí, Campinas, Capão Bonito e Cruzália.

\begin{tabular}{|c|c|c|c|}
\hline Linhagens e Cultivares & $\begin{array}{l}\text { Altura das plantas } \\
\mathrm{cm}\end{array}$ & $\begin{array}{c}\text { Acamamento } \\
\%\end{array}$ & $\begin{array}{c}\text { Ciclo emerg. floresc. } \\
\text { dias }\end{array}$ \\
\hline BH-1146 & $104 \mathrm{a}$ & 53 & $62 \mathrm{ab}$ \\
\hline Yavaros "S" & $67 \mathrm{~m}$ & 2 & $75 \mathrm{a}$ \\
\hline L-1 & $80 \mathrm{~g}-1$ & 22 & $60 \mathrm{~b}$ \\
\hline L-2 & $93 \mathrm{~b}-\mathrm{e}$ & 26 & $60 \mathrm{~b}$ \\
\hline L-3 & $77 \mathrm{i}-\mathrm{m}$ & 22 & $64 a b$ \\
\hline L-4 & $93 \mathrm{c}-\mathrm{e}$ & 22 & $60 \mathrm{~b}$ \\
\hline L-5 & $77 \mathrm{i}-\mathrm{m}$ & 11 & $59 \mathrm{~b}$ \\
\hline L-6 & $76 \mathrm{j}-\mathrm{m}$ & 29 & $63 a b$ \\
\hline L-7 & $79 \mathrm{~h}-\mathrm{l}$ & 31 & $64 a b$ \\
\hline L-8 & $91 b-f$ & 33 & $61 \mathrm{~b}$ \\
\hline L-9 & $82 \mathrm{f}-\mathrm{k}$ & 29 & $59 \mathrm{~b}$ \\
\hline L-10 & 83 e-k & 33 & $65 a b$ \\
\hline L-11 & $87 \mathrm{~d}-\mathrm{i}$ & 20 & $70 \mathrm{ab}$ \\
\hline L-12 & $100 \mathrm{ab}$ & 35 & $65 a b$ \\
\hline L-13 & $99 a-c$ & 42 & $64 a b$ \\
\hline L-14 & $97 \mathrm{a}-\mathrm{d}$ & 22 & $62 a b$ \\
\hline L-15 & $721-m$ & 4 & $67 a b$ \\
\hline L-16 & $88 \mathrm{~d}-\mathrm{h}$ & 22 & $64 \mathrm{ab}$ \\
\hline L-17 & $74 \mathrm{k}-\mathrm{m}$ & 9 & $67 a b$ \\
\hline L-18 & $89 c-h$ & 7 & $71 a b$ \\
\hline L-19 & $86 e-j$ & 15 & $69 a b$ \\
\hline L-20 & $85 e_{-j}$ & 15 & $69 a b$ \\
\hline L-21 & $85 \mathrm{e}-\mathrm{j}$ & 20 & $69 \mathrm{ab}$ \\
\hline L-22 & $90 \mathrm{~b}-\mathrm{g}$ & 22 & $64 a b$ \\
\hline L-23 & $89 \mathrm{c}-\mathrm{h}$ & 20 & $70 \mathrm{ab}$ \\
\hline F (experimentos) & $17,53 *$ & & $2,74 *$ \\
\hline d.m.s. (Tukey a 5\%) & 11 & & 14 \\
\hline C.V.\% & 7,69 & & 7,78 \\
\hline
\end{tabular}

*Significativo ao nível de $5 \%$.

(1) Médias seguidas de uma mesma letra em comum, não diferem pelo teste de Tukey.

(2) Refere-se somente aos ensaios instalados em Campinas (1990), Tatuí (1990) e Capão Bonito (1991 e 1992). 
TABELA 6 - Dados médios (1) referentes a comprimento da espiga, número de espiguetas por espiga, número de grãos por espiga e por espigueta e peso de 100 grãos dos genótipos de trigo avaliados nos ensaios de Campinas (1991) e Tatuí (1992).

\begin{tabular}{|c|c|c|c|c|c|}
\hline $\begin{array}{l}\text { Linhagens e } \\
\text { cultivares }\end{array}$ & $\begin{array}{l}\text { Comprimento da } \\
\text { espiga } \\
\mathrm{cm}\end{array}$ & $\begin{array}{l}\text { Espiguetas por } \\
\text { espiga }\end{array}$ & $\begin{array}{l}\text { Grãos por } \\
\text { espiga } \\
\quad n^{0} \\
\end{array}$ & $\begin{array}{l}\text { Grãos por } \\
\text { espigueta }\end{array}$ & $\begin{array}{l}\text { Peso de cem } \\
\text { grãos } \\
\text { g }\end{array}$ \\
\hline BH-1146 & $7,5 \mathrm{f}-\mathrm{h}$ & $18,3 \mathrm{~d}-\mathrm{g}$ & $26,5 \mathrm{c}$ & $1,44 \mathrm{~d}$ & 4,30 a-d \\
\hline Yavaros "S" & $6,6 \mathrm{~h}$ & $16,9 \mathrm{f}-\mathrm{g}$ & $48,5 \mathrm{ab}$ & $2,80 \mathrm{a}$ & 4,80 a-c \\
\hline L-1 & $7,0 \mathrm{gh}$ & $16,6 \mathrm{~g}$ & 33,5 a-c & 2,15 a-c & $3,80 \mathrm{c}-\mathrm{d}$ \\
\hline L-2 & $9,7 a b$ & $19,4 \mathrm{a}-\mathrm{g}$ & $40,2 a-c$ & $2,07 b-d$ & 4,82 a-c \\
\hline L-3 & $7,6 \mathrm{e}-\mathrm{h}$ & $17,2 \mathrm{e}-\mathrm{g}$ & $28,9 \mathrm{c}$ & $1,67 \mathrm{~cd}$ & $5,22 \mathrm{a}$ \\
\hline$L-4$ & 9,3 a-d & 19,2 a-g & 39,2 a-c & 2,04 b-d & 4,82 a-c \\
\hline L-5 & $7,8 \mathrm{~d}-\mathrm{h}$ & $17,2 \mathrm{e}-\mathrm{g}$ & 43,0 a-c & $2,49 a b$ & 4,04 b-d \\
\hline L-6 & $8,6 \mathrm{a}-\mathrm{g}$ & $17,3 \mathrm{e}-\mathrm{g}$ & 37,4 a-c & 2,15 a-c & 4,53 a-d \\
\hline L-7 & $8,2 b-h$ & $16,7 \mathrm{fg}$ & $33,1 a-c$ & 1,98 b-d & 4,61 a-d \\
\hline L-8 & $8,5 \mathrm{a}-\mathrm{g}$ & $16,3 \mathrm{~g}$ & 32,7 a-c & 2,02 b-d & 4,86 a-c \\
\hline L-9 & $10,0 \mathrm{a}$ & $18,5 \mathrm{~d}-\mathrm{g}$ & 34,0 a-c & $1,82 b-d$ & 4,65 a-d \\
\hline L-10 & $9,5 a-c$ & $18,4 \mathrm{~d}-\mathrm{g}$ & $31,7 \mathrm{bc}$ & $1,71 \mathrm{~cd}$ & 4,52 a-d \\
\hline L-11 & 9,0 a-f & $23,0 \mathrm{a}$ & 42,0 a-c & $1,85 \mathrm{~b}-\mathrm{d}$ & 4,36 a-d \\
\hline L-12 & $8,6 \mathrm{a}-\mathrm{g}$ & $18,5 \mathrm{~d}-\mathrm{g}$ & 39,2 a-c & $2,11 \mathrm{a}-\mathrm{d}$ & 4,67 a-d \\
\hline L-13 & 9,2 a-e & $18,9 \mathrm{c}-\mathrm{g}$ & 39,0 a-c & $2,07 b-d$ & $4,91 \mathrm{ab}$ \\
\hline L-14 & $8,6 \mathrm{a}-\mathrm{g}$ & $19,3 \mathrm{a}-\mathrm{g}$ & $38,2 \mathrm{a}-\mathrm{c}$ & $1,96 \mathrm{~b}-\mathrm{d}$ & 4,44 a-d \\
\hline L-15 & 9,2 a-e & 20,8 a-e & 42,6 a-c & 2,03 b-d & $4,59 \mathrm{a}-\mathrm{d}$ \\
\hline L-16 & $9,5 a-c$ & $18,9 \mathrm{c}-\mathrm{g}$ & 41,9 a-c & 2,19 a-c & $3,63 \mathrm{~d}$ \\
\hline L-17 & $9,5 \mathrm{a}-\mathrm{c}$ & 20,4 a-f & $44,6 \mathrm{a}-\mathrm{c}$ & $2,18 \mathrm{a}-\mathrm{c}$ & 4,44 a-d \\
\hline L-18 & $9,7 \mathrm{ab}$ & 19,0 b-g & 37,4 a-c & 1,94 b-d & 4,48 a-d \\
\hline L-19 & 9,2 a-e & 21,9 a-d & $49,2 \mathrm{ab}$ & $2,26 \mathrm{a}-\mathrm{c}$ & 4,47 a-d \\
\hline L-20 & 9,1 a-f & $22,9 \mathrm{a}$ & 42,9 a-c & $1,87 \mathrm{~b}-\mathrm{d}$ & 4,32 a-d \\
\hline L-21 & 9,3 a-d & 22,6 a-c & $51,2 \mathrm{a}$ & 2,27 a-c & 4,49 a-d \\
\hline L-22 & $7,9 \mathrm{c}-\mathrm{h}$ & $16,4 \mathrm{~g}$ & 34,0 a-c & 2,05 b-d & 4,35 a-d \\
\hline L-23 & 8,9 a-f & $22,8 \mathrm{ab}$ & 43,0 a-c & 1,88 b-d & 4,45 a-d \\
\hline$F$ (Experimentos) & $23,41 *$ & $12,14^{*}$ & $35,60 *$ & $40,24 *$ & $8,39 *$ \\
\hline F (Genótipos) & $9,43^{*}$ & $10,98 *$ & $3,52 *$ & $4,76^{*}$ & $3,26^{*}$ \\
\hline$F(G \times E)$ & 1,44 & $2,02 *$ & $3,04 *$ & $1,89 *$ & $3,25 *$ \\
\hline d.m.s.(Tukey a 5\%) & 1,7 & 3,9 & 19,3 & 0,71 & 1,09 \\
\hline C.V.\% & 6,82 & 6,03 & 11,96 & 10,69 & 5,68 \\
\hline
\end{tabular}

*Significativo ao nível de $5 \%$.; (1) Médias seguidas de uma mesma letra em comum, não diferem pelo teste de Tukey.

A linhagem 9 apresentou as espigas mais compridas diferindo na média dos dois experimentos, porém, somente dos cultivares controles e das linhagens $1,3,5,7$ e 22 . Em relação ao número de espiguetas por espiga as linhagens 11 e 20 apresentaram os maiores valores, utilizando a média dos dois ensaios considerados, não diferindo significativamente ao nível de $5 \%$ pelo teste de Tukey, das linhagens $2,4,14,15,17,19,21$ e 23 (TABELA 6).
Considerando o número de grãos por espiga verificou-se que a linhagem 21 foi a que apresentou o maior valor, porém, somente diferindo do cultivar BH-1146 e das linhagens 3 e 10.

O cultivar Yavaros "S" mostrou o maior número de grãos por espigueta, utilizando a média dos dois ensaios considerados, diferindo dos demais genótipos estudados, fazendo exceção, somente as linhagens $1,5,6,12,16,17,19$ e 21 . 
TABELA 7 - Comprimento médio das raízes dos genótipos de trigo estudados nos ensaios, medido após 72 horas de crescimento na solução nutritiva completa, que se seguiu a crescimento na solução tratamento contendo quatro níveis de $\mathrm{Al}^{3+}$.

\begin{tabular}{|c|c|c|c|c|}
\hline \multirow[t]{2}{*}{ Linhagens e Cultivares } & \multicolumn{4}{|c|}{ Concentração de Alumínio (mg/litro) } \\
\hline & $\mathbf{0}$ & 3 & 6 & 10 \\
\hline BH-1146 & 103,3 & 38,9 & 35,9 & 26,0 \\
\hline Yavaros"S" & 55,7 & 0,0 & 0,0 & 0,0 \\
\hline L-1 & 79,3 & 34,9 & 3,6 & 0,0 \\
\hline L-2 & 57,1 & 5,8 & 0,0 & 0,0 \\
\hline L-3 & 83,7 & 33,3 & 28,9 & 0,0 \\
\hline L-4 & 71,4 & 0,0 & 0,0 & 0,0 \\
\hline L-5 & 78,2 & 0,0 & 0,0 & 0,0 \\
\hline L-6 & 71,9 & 30,6 & 24,5 & 3,0 \\
\hline L-7 & 83,3 & 28,5 & 26,4 & 12,9 \\
\hline L-8 & 76,1 & 37,2 & 30,6 & 12,1 \\
\hline L-9 & 91,8 & 31,2 & 15,0 & 4,5 \\
\hline L-10 & 87,7 & 35,7 & 24,1 & 0,0 \\
\hline L-11 & 90,1 & 31,9 & 25,8 & 0,0 \\
\hline L-12 & 71,4 & 9,3 & 0,0 & 0,0 \\
\hline L-13 & 72,1 & 0,0 & 0,0 & 0,0 \\
\hline L-14 & 103,3 & 33,3 & 0,0 & 0,0 \\
\hline L-15 & 76,4 & 1,8 & 0,0 & 0,0 \\
\hline L-16 & 81,2 & 33,5 & 17,9 & 2,0 \\
\hline L-17 & 86,0 & 0,0 & 0,0 & 0,0 \\
\hline L-18 & 88,2 & 35,8 & 1,9 & 0,0 \\
\hline L-19 & 72,8 & 35,3 & 6,1 & 0,0 \\
\hline L-20 & 67,1 & 22,8 & 23,2 & 0,0 \\
\hline L-21 & 81,1 & 30,8 & 30,9 & 0,0 \\
\hline $\mathrm{L}-22$ & 76,2 & 42,5 & 24,3 & 21,7 \\
\hline L-23 & 81,4 & 26,2 & 17,3 & 2,2 \\
\hline
\end{tabular}

A linhagem 3 revelou os grãos mais pesados, considerando os dois experimentos, diferindo, porém, somente das linhagens 1,5 e 16.

A linhagem 9 mostrando espigas mais compridas; as linhagens 11 e 20 com maior número de espiguetas por espiga; a linhagem 21 revelando um grande número de grãos por espiga; o cultivar Yavaros "S" um maior número de grãos por espi- gueta e a linhagem 3 exibindo grãos pesados podem, representar fontes genéticas de relevância para essas características ao programa de melhoramento genético.

O comprimento médio das raízes das linhagens e dos dois cultivares, medido após 72 horas de crescimento, nas soluções nutritivas completas, que se seguiu a 48 horas de crescimento 
nas soluções de tratamento contendo quatro concentrações de alumínio, encontra-se na TABELA 7. Considerando-se $3 \mathrm{mg} /$ litro, pode-se verificar que as linhagens 4, 5, 13 e 17 e o cultivar Yavaros "S" não exibiram crescimento das raízes, sendo portanto considerados sensiveis à toxicidade de $\mathrm{Al}^{3+}$. Os demais genótipos estudados à exceção das linhagens $2,12,14$ e 15 foram considerados tolerantes à toxicidade de $\mathrm{Al}^{3+}$ por apresentarem crescimento das raízes quando se adicionaram $6 \mathrm{mg} / \mathrm{litro}$ de $\mathrm{Al}^{3+}$. $\mathrm{O}$ cultivar $\mathrm{BH}-1146 \mathrm{e}$ as linhagens $6,7,8$, $9,16,22$ e 23 mostraram os maiores crescimentos das raízes após permanecerem 48 horas em soluções contendo $10 \mathrm{mg} /$ litro de $\mathrm{Al}^{3+}$, sendo portanto considerados muito tolerantes.

Considerando-se as produções médias de grãos dos ensaios conduzidos em solo ácido de Capão Bonito (1991-92) - TABELA 2 - verificou-se que o cultivar Yavaros "S" e a linhagem 15 foram os menos produtivos e também sensíveis à concentração de $3 \mathrm{mg} /$ litro de $\mathrm{Al}^{3+}$ nas soluções nutritivas. As linhagens 11, 19, 21 e 23 e 0 cultivar $\mathrm{BH}-1146$, tolerantes à presença de $6 \mathrm{mg} /$ litro de $\mathrm{Al}^{3+}$ nas soluções nutritivas foram também os que mostraram as maiores produções de grãos considerando-se média dos ensaios de Capão Bonito. Esses resultados concordaram com os obtidos por CAMARGO et al., 1992.

As linhagens 11 e 19 tolerantes à toxicidade de alumínio foram as mais produtivas em Capão Bonito (solo ácido) e em solos corrigidos, com irrigação por aspersão em Campinas e Tatuí (TABELAS 1 e 2), resultados estes que discordaram dos obtidos por PRIOLI (1987), que mostrou em milho, uma associação entre baixa produtividade e tolerância ao $\mathrm{Al}^{3+}$ quando os híbridos foram avaliados em solos corrigidos (baixa acidez).

\section{CONCLUSÕES}

1. A seleção de linhagens obtidas através da irradiação com raios gama (27,5 krad) de sementes híbridas em geração $\mathrm{F}_{4}$ do cruzamento entre 0 cultivar BH 1146 ( $T$. aestivum L.) e a linhagem Anhinga "S" $x$ Winged "S" (T. durum L.) originou genótipos de alto potencial produtivo.

2. As linhagens 11 e 19 de porte médio, com moderada resistência ao acamamento, com ciclo médio da emergência ao florescimento, tolerantes à toxicidade de alumínio, destacaram-se quanto à produção de grãos, considerando-se os 9 experimentos.
3. As linhagens $4,15,18,19,20,21$ e 23 apresentaram moderada resistência ao agente causal de oídio, em estádio de planta adulta.

4. Todos os genótipos avaliados foram suscetíveis aos agentes causais das manchas foliares, havendo portanto a necessidade de serem incorporados fatores genéticos para resistência, através do programa de melhoramento.

5. O cultivar Yavaros " $S$ " e as linhagens 3, 5, 6, 15 e 17 apresentaram porte baixo, a linhagem 9 maior comprimento da espiga, as linhagens 11 e 20 grande número de espiguetas por espiga, a linhagem 21 maior número de grãos por espiga, o cultivar de trigo duro Yavaros " $\mathrm{S}$ " maior número de grãos por espigueta e a linhagem 3 grãos mais pesados. Esses genótipos poderiam ser usados como fontes genéticas para essas características.

6. O cultivar $\mathrm{BH}-1146 \mathrm{e}$ as linhagens $6,7,8,9$, 16, 22 e 23 foram consideradas as mais tolerantes à toxicidade de alumínio por mostrarem crescimento após serem cultivados em soluções nutritivas contendo $10 \mathrm{mg} /$ litro de $\mathrm{Al}^{3+}$.

\section{AGRADECIMENTOS}

Esta pesquisa teve suporte financeiro da International Atomic Energy Agency, Viena, Austria e da FAPESP, aos quais os autores agradecem.

\section{REFERÊNCIAS BIBLIOGRÁFICAS}

BATHIA, C.R. The use of mutagens for faciliting recombination. In: INTERNATIONAL ATOMIC ENERGY AGENCY. Manual on mutation breeding. Vienna: 1977. p.199.

CAMARGO, C.E. O.; OLIVEIRA, O.F. Tolerância de cultivares de trigo a diferentes níveis de alumínio em solução nutritiva e no solo. Bragantia, Campinas, v.40, p.21-31, 1991.

CAMARGO, C.E.O.; FELÍCIO, J.C.; ROCHA JUNIOR, L.S. Trigo:tolerância ao alumínio em solução nutritiva. Bragantia, Campinas, v.46, n.2, p.183-190, 1987.

CAMARGO, C.E. de O.; SANTOS, R.R.; PETTINELLI JUNIOR, A. Trigo duro: tolerância à toxicidade do alumínio em soluções nutritivas e no solo. Bragantia, Campinas, v.51, n.1, p.69-76, 1992. 
CAMARGO, C.E.0.; CAMARGO, C.R.O.; FELfCIO, J.C.; FERREIRA FILHO, W.P.; SANTOS, R.R.; DECOT, G. Avaliação das caracteristicas agronómicas e tecnologicas de genbtipos de trigo duro e triticale. Campinas:Instituto Agronômico, 1993, 27p. (IAC. Boletim Científico, 29).

HANSON, H.; BOURLAUG, N.E.; ANDERSON, R.C. Trigo en el Tercer Mundo. México: Centro International de Mejoramiento de Maiz y Trigo, 1982. $166 p$.

LI, J.; XU, X.; XUE, $X$.; WANG,T. Induced chromossome translocation by ionizing radiation in triticale $x$ wheat hybrids. Mutation Breeding Newsletter, Vienna, v.27, p.9-10, 1986.

MEHTA, Y.R. Doenças do trigo e seu controle. São Paulo: Agronômica Ceres, 1978. 190p. (Ceres, 20).

PRIOLI, A.J. Análise genética da tolerância à toxicidade do alumínio em milho (Zea mays L.). Campinas, 1987. 182 p. Tese (Doutorado) - Instituto de Biologia, Universidade Estadual de Campinas.

RAIJ, B. vab; SILVA, N.M.; BATAGLIA, O.C.; QUAGGIO, J.A.; HIROCE, R.; CANTARELLA, H.; BELLINAZZI JUNIOR, R.; DECHEN, A.R.; TRANI, P.E. Recomendaçōes de adubação e calagem para o Estado de São Paulo, Campinas: Instituto Agronômico, 1985. 107p. (IAC. Boletim Técnico, 100).
SÃO PAULO. Secretaria de Agricultura e Abastecimento. Relatorio do Acordo entre a SAA, atraves do Instituto Agronomico, e as Cooperativas Rurais do Vale do Paranapanema. Campinas: 1990-1992.

SCHRAMM, W; FULCO, W.S.; SOARES, M.H.G.; ALMEIDA, A.M. Resistência de cultivares de trigo em experimentação ou cultivo no Rio Grande do Sul, às principais doenças fúngicas. Agronomia Sulriograndense, Porto Alegre, v.10, n.1, p.31-52, 1974.

WANG, L.; FAN, O.; SHI, J.; WANG, Z. Induced mutations by irradiation of wheat Hybrids. Mutation Breeding Newsletter, Vienna, v.27, p.7, 1986.

WU, Z. Increasing segregation range in spring wheat by irradiation. Mutation Breeding Newsletter, Vienna, v.27, p.9, 1986.

ZHEN, Y.; SUN, G.; ZHANG, Y.; SHANG, $Z$. Breeding new disease resistant strains of wheat by using radiation and distant hybridization. Mutation Breeding Newsletter, Vienna, p.27, p.7-9, 1986.

Entregue para publicação em 21.06.94

Aceito para publicação em 20.08.94 